\title{
TRATAMENTO ENDOSCÓPICO DO CÂNCER EPIDERMÓIDE DO ESÔFAGO
}

\author{
Fauze MALUF-FILHO, Spencer CHENG e Gustavo de Oliveira LUZ
}

RESUMO - Objetivos - Procurou-se avaliar o papel atual dos procedimentos terapêuticos endoscópicos no manejo do pacientes com carcinoma epidermóide do esôfago. Levantamento de dados - Utilizando o banco de dados do PubMed (U.S. National Library of Medicine), analisaram-se as publicações sobre o tema nos últimos 10 anos, cotejando-as com a experiência desenvolvida no Serviço de Endoscopia Gastrointestinal do Departamento de Gastroenterologia da Faculdade de Medicina da Universidade de São Paulo. Síntese dos dados - Neste campo, destacam-se a ressecção endoscópica do câncer esofágico precoce e a tunelização do tumor avançado daquele órgão. A ressecção endoscópica da mucosa do câncer epidermóide precoce do esôfago é indicada quando a lesão é confinada ao epitélio (m1) ou à lamina própria (m2). A taxa de sobrevida conhecida de 5 anos após a ressecção endoscópica da mucosa do tumor epidermóide intramucoso do esôfago aproxima-se de $95 \%$. Conclusões - Baseado nas evidências disponíveis, parece razoável indicar a ressecção endoscópica da mucosa como tratamento de primeira escolha para pacientes com carcinoma esofágico epidermóide intramucoso. Existem vários métodos endoscópicos paliativos para o alívio da disfagia em câncer esofágico avançado. A escolha variará de acordo com as características anatômicas e a localização do tumor, as preferências do paciente, a disponibilidade e a capacitação do centro assistencial. A taxa de sucesso técnico da colocação de próteses metálicas auto-expansíveis em estenose maligna praticamente atinge $100 \%$. A taxa de efeito paliativo em longo prazo da disfagia aproxima-se de $80 \%$, o que faz com que esta opção seja, até o momento, o tratamento paliativo de escolha para os sintomas de obstrução causados pelo câncer esofágico de células escamosas.

DESCRITORES - Neoplasias esofágicas. Carcinoma de células escamosas. Esofagoscopia.

\section{INTRODUÇÃO}

A sobrevida de pacientes com câncer do esôfago depende do estádio da doença no momento do diagnóstico. Apesar dos avanços dos métodos de tratamento, tais como o acesso toracoscópico, a braquiterapia e os novos esquemas quimioterápicos, a paliação da disfagia e correção da desnutrição serão a única terapia a ser oferecida na maior parte destes enfermos ${ }^{(9)}$. Mais de $50 \%$ dos pacientes com câncer do esôfago apresentam doença incurável na primeira consulta, apenas 5\%-10\% deles estarão vivos passados 5 anos do diagnóstico da doença ${ }^{(11)}$.

A disfagia é o sintoma que mais incapacita, freqüentemente associada à caquexia, desconforto local e pneumonia de aspiração. A ressecção paliativa é associada a $20 \%-60 \%$ de morbidade e a $10 \%-33 \%$ de mortalidade ${ }^{(7)}$.

$\mathrm{O}$ tratamento combinado de radio e quimioterapia não alivia a disfagia de imediato, exigindo maior tempo de internação hospitalar. Ambas estão associadas à esofagite, com formação de fístula aerodigestiva em $20 \%-30 \%$ dos pacientes e à estenose actínica em 30\%-50\% dos casos ${ }^{(7)}$.

Existem vários métodos endoscópicos paliativos para o alívio da disfagia no câncer esofágico avançado. A escolha dependerá das características anatômicas e da localização do tumor, das preferências do paciente, do lugar e da capacitação disponível.

Por outro lado, em áreas de alto risco para tumores epidermóides de esôfago, tais como nas imediações das montanhas Taihang (China), o exame endoscópico com cromoscopia com iodo e biopsia de todas as lesões não coradas, seguido de ressecção endoscópica do carcinoma intramucoso, é considerado como a estratégia mais efetiva para incrementar a detecção precoce do câncer e reduzir a mortalidade ligada à doença. A proporção de detecção de tumor na sua fase inicial passa de $4 \%$ para $89 \%$ com a utilização desta estratégia ${ }^{(3)}$.

Nesta atualização, alguns aspectos básicos e outros controversos do tratamento endoscópico do câncer precoce e avançado do esôfago serão discutidos. 
Indicações, técnica e resultados do tratamento endoscópico do câncer precoce epidermóide do esôfago

A ressecção endoscópica da mucosa (REM) do câncer precoce epidermóide do esôfago é indicada quando a lesão está confinada ao epitélio (m1) ou à lâmina própria (m2). Entretanto, existem indicações estendidas. REM é habitualmente utilizada em combinação com a radioterapia para os pacientes de alto risco cirúrgico (Tabela 1). REM deveria ser preferida em relação aos métodos de ablação tais como a coagulação bipolar, o plasma de argônio ou o laser, uma vez que oferece amostra para a análise anatomopatológica.

Estes critérios rígidos para a indicação da REM visam à minimização do risco de presença de metástases nos linfonodos (Tabela 2).

TABELA 1 - Indicações para o tratamento endoscópico do câncer precoce do esôfago

\begin{tabular}{|c|c|c|}
\hline & Indicações & Indicações estendidas \\
\hline Profundidade de invasão & M1 e M2 & M3 e SM1 \\
\hline Tamanho & $<3 \mathrm{~cm}$ & $>3 \mathrm{~cm}$ \\
\hline $\begin{array}{l}\text { Envolvimento da } \\
\text { circunferência esofágica }\end{array}$ & $<3 / 4$ & $>3 / 4$ \\
\hline Número de lesões & até 4 & $>4$ \\
\hline Tipo histológico do tumor & $\begin{array}{l}\text { Carcinoma de célula escamosa bem } \\
\text { e/ou moderadamente diferenciado }\end{array}$ & $\begin{array}{c}\text { Adenocarcinoma bem } \\
\text { e/ou moderadamente } \\
\text { diferenciado }\end{array}$ \\
\hline Localização & Meio ou terço distal & $\begin{array}{l}\text { Esôfago cervical ou } \\
\text { abdominal }\end{array}$ \\
\hline Parede esofágica & Lateral e posterior & Anterior \\
\hline
\end{tabular}

TABELA 2 - O risco de metástases nos linfonodos no câncer esofágico precoce

\begin{tabular}{lc}
\hline Localização & Metástase linfonodal - \%* \\
\hline M1 & 0 \\
M2 & 1 \\
M3 & 5 \\
Sm1 & 20 \\
Sm2 & 30 \\
Sm3 & 40 \\
\hline * Dados obtidos de estudo multicêntrico, envolvendo 1690 lesões diagnosticadas em 143 instituições no \\
Japão(b)
\end{tabular}

Feita a detecção do carcinoma superficial epidermóide do esôfago, o estádio com ultra-som endoscópico (ecoendoscopia) deve ser indicado para confirmar a integridade da camada submucosa hiperecóica. As mini-sondas de alta freqüência $(20$ ou $30 \mathrm{MHz})$ são preferidas em relação à sonda padrão (aparelho 7,5 MHz). MURATA et al. ${ }^{(12)}$ e MALUF-FILHO et al. ${ }^{(1)}$ encontraram, respectivamente, $84 \%$ e $90 \%$ de precisão na ecoendoscopia de alta freqüência para diferenciar tumores restritos à mucosa de lesões que invadiam a camada sub-mucosa.

\section{Técnica da REM}

Algumas modificações técnicas foram descritas a respeito da técnica REM original, mas a maior parte delas segue algumas etapas básicas.
1. Demarcação da lesão - o uso de lugol em solução a $2 \%$ ou 2,5\% para o carcinoma esofágico de células escamosas é quase imperativo. Entretanto, a coloração desaparece habitualmente durante o processo. Por esta razão, é recomendado demarcar as margens da lesão com a utilização de pontos de eletrocoagulação.

2. Injeção na lesão ou "lifting" - a injeção de solução salina na submucosa tem três intenções: 1: para separar a lesão da muscularis propria (MP). A coagulação e a necrose da camada MP é o mecanismo de perfuração causado pela REM. É também provável que a injeção impeça o sangramento pela separação da lesão dos vasos mais profundos e mais calibrosos. Quando a solução salina é utilizada, é freqüente injetá-la ou reinjetá-la várias vezes durante a ressecção de uma lesão maior. Em algumas ocasiões, até 30-50 mL de solução salina são injetadas durante a sessão. 2: para criar bolha mais fácil de agarrar e cortar. 3: a ausência de sinal de "lifting" durante a injeção é sinal fortemente sugestivo da invasão submucosa ou da presença de fibrose.

Não se recomenda o uso de vasoconstritor associado à solução salina para a injeção durante a REM, pois não se evita sangramento maior com tal medida. Por outro lado, se a vasoconstrição é importante, a lesão neoplásica se torna isquêmica e pouco visível. Recentemente, outras soluções foram sugeridas para substituir a solução salina. $\mathrm{O}$ manitol e o hialuronidato de sódio têm a vantagem de permanecer por mais tempo na submucosa. O manitol em solução de $20 \%$ é substância facilmente disponível e de baixo custo.

Recomenda-se injetá-los inicialmente na margem distal da lesão, assim a bolha formada levará a lesão à vista do profissional.

3. A lesão pode ser agarrada ou sugada num cilindro incolor adaptado à extremidade distal "cap" ou num tubo especialmente desenhado para esta finalidade. Fórceps maiores com braços mais compridos são úteis para a REM. Endoscópio de duplo canal é necessário para esta técnica. Se apenas endoscópio padrão for disponível, a técnica do "cap" de INOUE et al.(5) é maneira elegante de fazer a ressecção da lesão. Ligadura da lesão é também possível. O problema com as técnicas do "cap" ou da ligadura é que ambas fornecem amostras pequenas. Para eliminar esta limitação, "caps" maiores feitos de material macio foram comercializadas. Outra possibilidade é o uso de alça de polipectomia monofilamentar, rígida. Quando o órgão é desinsuflado, a alça é fechada e o tecido é agarrado. Deve ser reconhecido que agarrar a lesão com fórceps permite visibilidade melhor de sua captura. As lesões maiores que $2,0 \mathrm{~cm}$ são habitualmente removidas em vários segmentos ("piece-meal").

4. As margens da ulceração resultante são verificadas em relação à presença de lesão residual. Qualquer dúvida sobre a presença de câncer residual dever indicar ressecção complementar. O uso de coagulação por plasma de argônio ou de laser é também possível para esta finalidade. Ela deve ser utilizada quando não for possível remover a margem duvidosa da ulceração. Ao final do procedimento, biopsias devem ser coletadas das margens da ulceração. 
5. As amostras recolhidas devem ser esticadas e fixadas numa superfície firme e a lesão deve ser reconstruída para facilitar o exame histopatológico. A presença do patologista durante o procedimento representa a situação ideal.

6. O patologista deve dar algumas informações sobre a lesão:

- tipo histológico do tumor;

- margens removidas;

- profundidade da invasão;

- envolvimento dos vasos linfáticos e sangüíneos

Se a análise da amostra revela carcinoma indiferenciado ou invasão de submucosa ou embolia venosa/linfática, cirurgia convencional com linfadenectomia é recomendada. Comprovado o envolvimento neoplásico das margens da lesão, estas devem ser removidas ou destruídas por plasma de argônio ou laser durante as 3 primeiras semanas após a REM.

7. Inibidores de bomba de prótons em dose padrão devem ser prescritos após REM esofágica, gástrica ou duodenal, durante 8 semanas. O uso de antibióticos e a colocação endoscópica de clipes são obrigatórios quando há suspeita de perfuração.

8. Após REM de câncer esofágico precoce, o paciente deve ser examinado a cada 3 meses no primeiro ano, a cada 6 meses no segundo ano e anualmente, durante 5 anos. Em todas as situações, a cicatriz deve ser biopsiada.

Algumas variantes técnicas são úteis para superar as dificuldades habitualmente encontradas durante a REM (Tabela 3 ).

TABELA 3 - Problemas e soluções técnicas em REM do câncer esofágico precoce de células escamosas

\begin{tabular}{lc}
\hline Problema & Solução \\
\hline $\begin{array}{l}\text { Lesão localizada nas paredes anteriores ou } \\
\text { laterais do esôfago }\end{array}$ & $\begin{array}{c}\text { Virar em sentido anti-horário o } \\
\text { endoscópio até que a lesão se apresente } \\
\text { às "6 horas" }\end{array}$ \\
$\begin{array}{l}\text { Lesão localizada próximo ao esfíncter } \\
\text { esofágico superior ou inferior }\end{array}$ & $\begin{array}{c}\text { Uso da técnica de CAP de INOUE } \\
\text { Lesão maior que 15 mm }\end{array}$ \\
$\begin{array}{c}\text { Preferir a técnica de "strip-biopsy" ou } \\
\text { "caps" maiores Injetar soluções que ficam } \\
\text { mais tempo na submucosa, } \\
\text { por exemplo manitol } \\
\text { Endoscópio de duplo canal não disponível } \\
\text { Usar técnica de CAP de Inoue ou usar } \\
\text { uma alça mono-fio (ASMono - Wilson } \\
\text { Cook) ou uma alça de } \\
\text { "dente-de- tubarão" }\end{array}$ \\
\hline
\end{tabular}

Quando a REM é indicada para o tratamento de câncer epidermóide do esôfago, a questão seguinte não deve ser esquecida: Será que a REM é tão efetiva quanto à esofagectomia para o tratamento deste tumor?

A taxa de sobrevida de 5 anos após a REM de tumor epidermóide intramucoso aproxima-se de 95\% (Tabela 4). Entretanto, não existem ensaios aleatórios controlados que a comparem à esofagectomia. Baseado numa pesquisa centrada em respostas a questionários enviados a alguns centros no Japão, KODAMA e KAKEGAWA ${ }^{(5)}$ estudaram os resultados de 396 pacientes submetidos a REM ou esofagectomia por câncer epidermóide de esôfago entre 1990 e 1994. As taxas de sobrevida foram semelhantes para ambos os grupos.

Baseado nas evidências disponíveis, parece razoável a indicação da REM como tratamento de primeira escolha para pacientes com carcinoma epidérmoide intramucoso esofágico ${ }^{(16)}$.
TABELA 4 - Resultados e complicações da REM

\begin{tabular}{lcccc}
\hline Autor (ano) & n & $\begin{array}{c}\text { Taxa de sobrevida } \\
\text { de } 5 \text { anos }(\%)^{*}\end{array}$ & $\begin{array}{c}\text { Complicações } \\
(\%)\end{array}$ \\
\hline Esôfago & Inoue et al.(1999)(7) & 142 & 100 & $\begin{array}{c}\text { Perfuração }(0,7) \\
\text { Estenose }(0,7)\end{array}$ \\
& Makuuchi (2001) $)^{(10)}$ & 249 & 97,9 & Não relatada \\
\hline * Taxa de sobrevida de doença específica & & &
\end{tabular}

\section{MODALIDADES DE PALIAÇÃO ENDOSCÓPICA DA DISFAGIA PROVOCADA PELO CARCINOMA ESOFÁGICO EPIDÉRMOIDE AVANÇADO}

\section{Dilatação}

Pode ser realizada com balões expansíveis ou velas (sondas de polivinil guiadas por fio, sob controle fluoroscópico, que permitem o consumo de dieta pastosa Os benefícios são habitualmente de curta duração, medidos em dias, até que outros métodos mais duradouros para o alívio da disfagia sejam exigidos.

\section{Laser Nd-YAG}

O uso do laser no câncer esofágico obstrutivo é o modo mais efetivo de ablação térmica. Ele oferece maior duração de alívio da disfagia e baixas taxas de complicações. Não é útil para a compressão extrínseca, mas pode ser mais apropriado para tumores exofíticos altos não-circunferenciais, nos quais a inserção de próteses pode ser difícil ou menos eficaz para alívio da disfagia.

O tratamento endoscópico com laser Nd-YAG de alta potência oferece efeito paliativo da disfagia pela coagulação e vaporização do tecido maligno sob visualização direta ${ }^{(7,9)}$.

$\mathrm{O}$ laser pode ser usado numa abordagem para melhoria em lesões extensas mas, idealmente, permite apenas o tratamento de segmentos curtos devido ao acúmulo de resíduos necrosados e edema do tecido. Pode ser usado também de maneira retrógrada circunferencial após dilatação preliminar, permitindo o tratamento de lesões maiores, com melhora da disfagia e menor número de sessões de tratamento. Por vezes, trata-se de procedimento difícil e de longa duração com maiores taxas de complicações. $\mathrm{O}$ uso de anestesia geral oferece proteção da via aérea e minimiza o desconforto do paciente durante o procedimento ${ }^{(6)}$. Cabe acrescentar que se trata de método dispendioso e praticamente indisponível em nosso meio.

\section{Eletrocauterização}

As eletrocauterizações mono e bipolar são pouco usadas no tratamento de tumores esofágicos avançados. O BICAP (cauterizador bipolar circunferencial) tem taxa de perfuração elevada. Além disso, requer mais do que uma sessão de tratamento e tem dispersão de energia de $360^{\circ}$, podendo ser usado apenas em lesões completamente circunferenciais.

A coagulação por plasma de argônio, modo de cauterização com gás argônio ionizado, foi usada para tratar tumores precoces e hipertrofia de tumor em pacientes com próteses metálicas auto-expansíveis. Sua penetração em profundidade é limitada (2-3 mm) e não é tão efetiva quanto o laser no tratamento de tumores volumosos ${ }^{(7)}$. 


\section{Terapia por injeção}

É a técnica endoscópica menos cara, sendo o álcool absoluto o agente esclerosante mais usado. A experiência com este método é limitada a algumas séries de casos. Dor torácica é a complicação mais comum. Os pacientes precisam habitualmente de reintervenção dentro de 5 semanas. Esta modalidade é mais conveniente para pequenos tumores exofíticos localizados.

\section{Terapia fotodinâmica}

Envolve a interação de luz administrada após a introdução de agente foto-sensibilizador que se concentra preferencialmente no tecido tumoral. A reação fotoquímica acontece com a exposição do tumor à luz vermelha, proveniente de difusor laser de baixa potência, guiada endoscopicamente. A profundidade de penetração é de aproximadamente $5 \mathrm{~mm}$ e o efeito paliativo é comparável ao que se consegue com o laser Nd-YAG. Contudo, trata-se de procedimento tecnicamente fácil e mais confortável para o paciente. O maior problema é a retenção da droga fotossensível na pele durante aproximadamente 6 semanas após sua injeção e a necessidade de se evitar exposição direta ao sol durante este tempo, sob pena de queimaduras solares graves ${ }^{(7)}$. Acrescente-se a isto $\mathrm{o}$ seu alto custo e a baixa disponibilidade.

\section{Endopróteses plásticas e auto-expansíveis}

A colocação de próteses endoscópicas em obstrução esofágica maligna apresenta a vantagem de alívio instantâneo da disfagia e controle de fístula traqueoesofágica ${ }^{(1,13)}$.

O primeiro dispositivo com este fim foi feito de marfim descalcificado e colocado por Leroy d'Etiolles em 1845. Em 1887, Sir Charles Symonds utilizou um objeto de metal. Nas décadas de 50 e 60, os tubos de Mousseau e de Celestin, ambos inseridos por tração através de laparotomia, foram amplamente utilizados. Em 1977, um tubo de pulsão, inserido endoscopicamente sem necessidade de laparotomia, foi introduzido por Atkinson e Ferguson ${ }^{(7)}$.

Apesar dos tubos de plástico semi-rígidos serem menos caros, o procedimento de inserção é traumático e associado a taxas elevadas de complicações imediatas (5\%-15\%) e mortalidade $(2 \%-4 \%)^{(1,7,9,13)}$. Nos dias atuais, alguns ainda conferem às próteses plásticas indicação para tratamento da disfagia em pacientes com tumores localizados na parte mediana reta do esôfago, sem angulação aguda do lúmen, quando nenhuma dilatação previa é requerida. Em algumas regiões do mundo, próteses plásticas de pequeno diâmetro são utilizadas como alternativa de baixo custo. Próteses plásticas expansíveis foram desenvolvidas para oferecer uma inserção mais fácil, com alguma diminuição do custo $^{(7,9)}$. Em estudo comparativo com próteses de plástico e metálicas auto-expansíveis, os resultados imediatos foram similares. A médio prazo, as obstruções foram mais freqüentes no grupo do tipo metálico ${ }^{(13)}$.

As próteses metálicas auto-expansíveis foram desenvolvidas para o controle de doença maligna do esôfago na década de 90 e trouxeram esperança para o tratamento desta doença, dada a facilidade de sua inserção, diâmetro interno maior $(18-25 \mathrm{~mm})$, baixo risco de perfuração, potencial para utilização em doenças da parede esofágica e do mediastino posterior, potencial para serem terapia única, possibilidade de inserção através de estruturas estreitas sem exigir dilatação vigorosa.
As próteses disponíveis comercialmente são apresentadas na lista seguinte ${ }^{(7)}$ :

- Wallstent (revestidos e não revestidos) (Schneider AG, Minneapolis, MN, EUA)

- Ultraflex (revestidas e não revestidas) (Microvasive/Boston Scientific Corp, Watertown, EUA)

- Gianturco Z-stents (revestidas e não revestidas) (WilsonCook, Winston -Salem, NC, EUA)

- Esophacoil (Medtronic InStent Inc, Eden Prairie, MN, EUA)

- Song/Korean (Sooho Medi-tech Co, Seoul, Coréia)

- Japanese (Soa-Tech, Showa, Himeji, Japão)

As primeiras próteses utilizadas foram os Wallstents, cujo modelo foi inspirado nos modelos biliares. O Wallstent é feito de liga biomédica não-magnética de cobalto-cromo, disponível nas formas não revestidos ou revestidos de polímero de silicone Permalume. A endoprótese Wallstent esofágica é apresentada em duas configurações: o Wallstent Esophageal I (sistema de colocação 38F), caracterizada pelo seu formato de "osso de cachorro", e o Wallstent Esophageal II (sistema de colocação 18F), com formato encurvado, introduzidos em 1994 e 1997, respectivamente.

O stent Ultraflex consiste em um tubo de fios trançados de nitinol (liga de níquel e titânio) revestido por poliuretano até $1,5 \mathrm{~cm}$ dentro de cada lado, pontas de formato encurvado de $23 \mathrm{~mm}$ e $28 \mathrm{~mm}$, diâmetro do corpo $17 \mathrm{~mm}$ ( $18 \mathrm{~mm}$ no modelo não-revestido), $7,10,12 \mathrm{~cm}$ de comprimento (e $15 \mathrm{~cm}$ no modelo de $23 \mathrm{~mm}$ ), sistema de colocação com ponta distal medindo $21 \mathrm{~F}$.

O Z-stent é uma série de gaiolas de fios de aço inoxidável encurvados em segmentos curtos, numa configuração de zigzag, costurados juntos e revestidos de uretano; o último modelo (chamado "G") possui diâmetro interno de $18 \mathrm{~mm}$, pontas reforçadas de $25 \mathrm{~mm}$ no funil proximal e distal, comprimento de 6 a $14 \mathrm{~cm}$ e um sistema de colocação de diâmetro 28F.

O Esophacoil é prótese de mola feita de um único fio achatado de nitinol, enrolado numa configuração de bobina com pontas reforçadas de $2 \mathrm{~cm}$ e não é revestida. O sistema de colocação tem diâmetro de $32 \mathrm{Fr}$. As próteses têm comprimento 10 e $15 \mathrm{~cm}$ e diâmetros internos de 14, 16, 18, e $20 \mathrm{~mm}^{(4,7,9)}$.

Estudo de comparação das propriedades físicas de cinco próteses metálicas esofágicas auto-expansíveis mostrou que o Esophacoil tem a força de expansão maior, seguido pelos Wallstent, Song e Z-stent, respectivamente (Tabela 5). O Ultraflex tem a menor força de expansão. O Esophacoil apresenta também a maior resistência a se moldar a estenoses tortuosas, seguido pelos Wallstent e Ultraflex. O Song e o Z-stent têm um raio de anel $>200 \mathrm{~mm}$, o que indica que eles podem fraturar já numa configuração pouco distorcida ${ }^{(1)}$.

Em pesquisa nacional nos Estados Unidos, RAMIREZ et al. ${ }^{(13)}$ relatam resultados técnicos sobre a colocação de próteses metálicas auto-expansíveis. Avaliaram a necessidade de dilatação antes da colocação das próteses, orientação para a expansão e verificação da patência e da posição. A dilatação antes da colocação da prótese foi realizada sobre fio-guia $(65 \%)$ e com balão que é passado através do canal de biopsia do endoscópio ("through-the-scope") (31\%). Na maior parte dos casos (83\%), a colocação de prótese foi feita através de orientação endoscópica e fluoroscópica. Em apenas $15 \%$ dos casos, a expansão da 
TABELA 5 - Comparação das propriedades físicas de 5 endopróteses plásticas e auto-expansíveis

\begin{tabular}{|c|c|c|c|c|c|}
\hline $\begin{array}{l}\text { Próteses } \\
\text { metálicas }\end{array}$ & \multicolumn{2}{|c|}{$\begin{array}{l}\text { Comprimento/ } \\
\text { diâmetro }(\mathrm{mm})\end{array}$} & \multicolumn{2}{|c|}{$\begin{array}{l}\text { Força de expansão } \\
(\mathrm{N} / \mathrm{mm} / \mathrm{cm})\end{array}$} & $\begin{array}{l}\text { Raio de anel } \\
\qquad(\mathrm{mm})\end{array}$ \\
\hline Esophacoil & \multicolumn{2}{|c|}{$160 / 18$} & \multicolumn{2}{|l|}{63.5} & 22 \\
\hline Wallstent & \multicolumn{2}{|c|}{$115 / 19$} & \multicolumn{2}{|l|}{0.748} & 30 \\
\hline Z-stent & \multicolumn{2}{|c|}{$80 / 19$} & \multicolumn{2}{|l|}{0.283} & $>200$ \\
\hline Song & \multicolumn{2}{|c|}{$125 / 15,5$} & \multicolumn{2}{|l|}{0.277} & $>200$ \\
\hline Ultraflex & \multicolumn{2}{|c|}{$100 / 17,5$} & \multicolumn{2}{|l|}{0.094} & 41 \\
\hline \multicolumn{6}{|l|}{ Chan et al. 1999(1) } \\
\hline & Esophacoil & Ultraflex & Wallstent I & Wallstent II & Z-stent \\
\hline Material & Nitinol & Nitinol & Elgiloy & Elgiloy & $\begin{array}{c}\text { Aço } \\
\text { inoxidável }\end{array}$ \\
\hline $\begin{array}{l}\text { Diâmetro do } \\
\text { sistema de } \\
\text { colocação (F) }\end{array}$ & 32 & 24 & 38 & 18 & 28 \\
\hline Revestimento & Não & Sim & Sim & Sim & Sim \\
\hline Modelo & Bobina & Tela & Tela & Tela & Zig-zag \\
\hline Força radial & +++++ & + & ++++ & +++ & ++ \\
\hline $\begin{array}{l}\text { Diâmetro do } \\
\text { lúmen }(\mathrm{mm})\end{array}$ & $14,16,18,20$ & 16,18 & 18 & 19 & 18 \\
\hline $\begin{array}{l}\text { Fechamento da } \\
\text { fístula }\end{array}$ & Possível & Sim & Sim & Sim & Sim \\
\hline $\begin{array}{l}\text { Grau de } \\
\text { encolhimento }(\%)\end{array}$ & 50 & $30-40$ & 20 & 30 & $0-10$ \\
\hline
\end{tabular}

prótese foi feita exclusivamente sob a visão fluoroscópica. A orientação endoscópica foi usada exclusivamente em $2 \%$ dos pacientes. A verificação da permeabilidade e da posição foi realizada por observação endoscópica através da prótese em $61 \%$, radioscopia em $36 \%$, esofagograma baritado no mesmo dia em $11 \%$, e esofagograma baritado no dia seguinte em $19 \%$ dos casos. A falha na expansão da prótese foi relatada em 7\%, mal posicionamento em $4,8 \%$ e falha da liberação da prótese do seu sistema introdutor em 3\%. Complicações imediatas foram dor torácica grave em $5,5 \%$, migração em 1,6\%, perfuração em $1,1 \%$ e óbito relacionado com a colocação em $0,5 \%$. Complicações não imediatas compreenderam disfagia recurrente com $9 \%$, óbito dentro de 30 dias em $7 \%$, crescimento interno de tumor em $6 \%$, sintomas de refluxo grave em $5 \%$, migração em $3 \%$, desenvolvimento de fístula traqueoesofágica em $1 \%$, sangramento em $0,5 \%$ e perfuração em $0,5 \%$ dos pacientes.

As próteses revestidas representam o tratamento de escolha para o controle das fístulas traqueoesofágicas. O efeito paliativo foi bem sucedido em $70 \%-80 \%$ dos casos. Entretanto, o aumento da fístula ou formação de outra podem acontecer. Os pacientes com estenose traqueobronquial devem ter sua estenose respiratória tratada em primeiro lugar ${ }^{(8,9)}$.

A colocação de próteses através da junção esôfago-gástrica constitui-se problema particular. Em comparação com as próteses colocadas para lesões mais proximais, o efeito paliativo é menor e pode ter taxa de complicações maior ${ }^{(8)}$. Próteses especialmente desenhadas foram desenvolvidas para esta localização. O Wallstent Flamingo é um stent cônico concebido para aplicar força radial variável ao longo do comprimento do stent, para atender às diferenças anatômicas no esôfago distal e na cárdia. A camada de poliuretano reveste internamente a prótese, estendendo-se até $2 \mathrm{~cm}$ de distância de ambas as pontas. Próteses de grande diâmetro (diâmetros proximal - $30 \mathrm{~mm}$ e distal - $20 \mathrm{~mm}$ ), e diâmetro menor (diâmetros proximal - $24 \mathrm{~mm}$ e distal $16 \mathrm{~mm}$ ) são disponíveis. O diâmetro interno da prótese permanece inalterado, mesmo quando angulado.

Um Z-stent modificado foi comercializado como paliativo do câncer da cárdia. Neste modelo o revestimento de poliuretano estende-se distalmente para formar uma válvula anti-refluxo. Os dados sobre os primeiros testes usando este novo dispositivo mostraram que tempo de exposição ao ácido esofágico é menor do que as próteses padrão ( $1 \%$ versus $49 \%$ respectivamente $P=0.03)$, com eficácia equivalente quanto à paliação da disfagia ${ }^{(14)}$.

$\mathrm{Na}$ tentativa de reduzir a migração distal dessas próteses, foi desenvolvida prótese revestida que pode ser fixada por uma linha de seda ao lobo da orelha do paciente. Taxa notável de $0 \%$ de deslocamento da prótese e taxa de oclusão de $3 \%$ foram obtidas durante o acompanhamento médio de 7.5 meses $^{(8,14)}$.

O deslocamento da prótese no esôfago distal é mais provável do que com próteses colocadas para tumores localizados em região mais proximal porque a parte distal do stent se projeta livremente para o fundo do estômago. Aumento da incidência de sangramento foi relatado e pode ser explicado por dois fatores: a) a erosão da ponta distal do stent na parede posterior do estômago, da qual resultam ulceração e sangramento posterior; b) a prótese atravessando a junção gastroesofágica não ficará retificada por causa do ângulo anatômico normal entre o esôfago e a cárdia gástrica. A força lateral assimétrica exercida pela parte proximal da prótese localizada no esôfago acima do tumor, provoca aumento da taxa de complicações relacionadas à pressão, tal como ulceração e sangramento. Esta angulação também pode explicar a menor eficiência no alívio da disfagia.

A taxa de sucesso técnico da colocação de prótese metálica atravessando a junção gastroesofágica é próxima de $100 \%$. Porém alguns pacientes com câncer avançado do esôfago distal/cárdia não terão alívio da disfagia por causa de outros locais de obstrução não identificados, de carcinomatose peritonial freqüente ou de paresia gástrica devida ao envolvimento neural pelo tumor.

As complicações que se seguem à colocação de prótese metálica incluem pneumonia por aspiração, dor torácica, perfuração, sangramento e febre. Elas ocorrem em 20\%-30\% dos pacientes. Complicações tardias compreendem sangramento, formação de fístula, refluxo gastroesofágico, migração, obstrução por bolo alimentar e crescimento tumoral. Acontecem em $35 \%-45 \%$ dos pacientes.

Radiação e/ou quimioterapia, antes ou após a colocação da prótese, podem aumentar os riscos das complicações acima descritas, especialmente quando se aplicam próteses com maior poder de expansão radial. Entretanto, trata-se de assunto controverso, em avaliação ${ }^{(14,17)}$. Não é prática da presente equipe irradiar tumor esofágico em paciente com prótese autoexpansível. Procura-se indicar a prótese para aqueles que já foram submetidos a rádio-quimioterapia quando apresentam disfagia devido à recurrência da doença. 
O Z-stent com válvula anti-refluxo foi avaliado no Hospital de Clínicas da Universidade de São Paulo. CHENG ${ }^{(2)}$ colocou 26 Z-stents com mecanismo anti-refluxo, desenvolvido pelo médico indiano Dua, em pacientes com câncer inoperável da junção gastroesofágica. Os pacientes foram seguidos até a morte com taxa média de sobrevida de 75,6 dias. A colocação foi bem sucedida em
25 pacientes (96\%). A disfagia melhorou em 22 (85\%) e não mudou em 3 pacientes $(12 \%)$. Um paciente teve sintoma de regurgitação mas não teve refluxo na pesquisa com bário. As complicações mais freqüentes foram dor torácica em 13 enfermos $(50 \%)$, perfuração em $3(12 \%)$, sangramento em 7 (27\%), deslocamento em $3(12 \%)$ e ruptura da válvula em 4 (15\%).

Maluf-Filho F, Cheng S, Luz GO. Endoscopic treatment of squamous cell esophageal cancer. Arq Gastroenterol. 2006;43(2):132-7.

ABSTRACT - Objective - In this article, it was evaluated the role of endoscopic procedures for the management of squamous cell esophageal cancer. Data source - Relevant publications cited at PubMed database in the last 10 years were analyzed and compared with the experience developed at the Gastrointestinal Endoscopy Division of the Department of Gastroenterology of the University of São Paulo School of Medicine. Mucosectomy and advanced tumor tunnelization were the most important developments in that area. Data synthesis - Endoscopic mucosal resection of early epidermoid cancer of the esophagus is indicated when the lesion is confined to the epithelium (m1) or to the lamina propria $(\mathrm{m} 2)$. The described 5-year survival rate after endoscopic mucosal resection of intramucosal epidermoid tumor of the esophagus approaches $95 \%$. Based on the available evidence, it seems reasonable to indicate endoscopic mucosal resection as a first-choice treatment for patients with intramucosal epidermoid esophageal carcinoma. There are a variety of endoscopic palliative methods for dysphagia relief in advanced esophageal cancer. Conclusions - The choice will vary according to the anatomical features and location of the tumor, patient preferences, local and expertise availability. The technical success rate for placement of metal stents across the malignant stenosis is close to $100 \%$. The rate of long-term palliation of dysphagia approaches $80 \%$ which makes expandable metal stents the treatment of choice for palliation of obstructive symptoms caused by advanced squamous cell cancer of the esophagus.

HEADINGS - Esophageal neoplasms. Carcinoma, squamous cell. Esophagoscopy.

\section{REFERÊNCIAS BIBLIOGRÁFICAS}

1. Chan AC, Shin FG, Lam YH, Ng EK, Sung JJ, Lau JY, Chung SC. A comparison study on physical properties of self-expandable esophageal metal stents. Gastrointest Endosc. 1999; 49:462-5.

2. Cheng S. Tratamento dos tumores avançados da junção esôfago-gástrica por prótese auto-expansível com válvula anti-refluxo [dissertação]. São Paulo: Faculdade de Medicina da Universidade de São Paulo; 2005.

3. Dong A, Tang P, Li L, Wang G. The strategy for esophageal cancer control in high-risk areas of China. Jap J Clin Oncol. 2002;32:s10-s2.

4. Expandable metal stents. Gastrointest Endosc Clin N Am. 1999;9:3.

5. Inoue H, Tani M, Nagai K, Kawano T, Takeshita K, Endo M, Iwai T. Treatment of esophageal and gastric tumors. Endoscopy. 1999;31:47-55.

6. Kodama M, Kakegawa T. Treatment of superficial cancer of the esophagus: a summary of responses to a questionnaire on superficial cancer of the esophagus in Japan. Surgery. 1998;123:432-9.

7. Kubba AK, Krasner N. An update in the palliative management of malignant dysphagia. Eur J Surg Oncol. 2000;26:116-29.

8. Leiper K, Morris AI. Treatment of oesophago-gastric tumors. Endoscopy. 2002;34:139-45.

9. Lightdale CJ. Esophageal cancer: practice guidelines. Am J Gastroenterol. 1999;94:20-9.

10. Makuuchi H. Endoscopic mucosal resection for mucosal cancer in the esophagus. Gastrointest Endosc Clin N Am. 2001;11:445-8

11. Maluf-Filho F, Matuguma S, Marques P, Sakai P, Ishioka S, Cecconllo I, GamaRodrigues J. Accuracy of $30 \mathrm{Mhz}$ for superficial esophageal and gastric cancer: can submucosal invasion be reliably detected?[abstract]. Gastrointest Endosc. 2002;55: $\mathrm{AB} 233$.

12. Murata Y, Suzuki S, Ohta M, Mitsunaga A, Hayashi K, Yoshida K, Ide H. Small ultrasonic probes for determination of the depth of superficial esophageal cancer. Gastrointest Endosc. 1996:44:23-8.
13. Ramirez FC, Dennert B, Zierer ST, Sanowsky RA. Esophageal self-expandable metallic stents - indications, practice, techniques, and complications: results of a national survey. Gastrointest Endosc. 1997;45:360-4.

14. Siersema PD, Marcon N, Vakil N. Metal stents for tumors of the distal esophagus and gastric cardia. Endoscopy 2003;35:79-85.

15. Simmons DT, Baron TH. Endoluminal palliation. Gastrointest Endosc Clin N Am. 2005; $15: 467-84$

16. Soetikno RM, Gotoda T, NakanishiY, Soehendra N. Technological review-Endoscopic mucosal resection. Gastrointest Endosc. 2003;57:567-79.

17. Sumiyoshi T, Gotoda T, Muro K, Rembacken B, Goto M, Sumiyoshi Y, Ono H, Saito D. Morbidity and mortality after self-expandable metallic stent placement in patients with progressive or recurrent esophageal cancer after chemoradiotherapy. Gastrointest Endosc. 2003;57:882-5. 